\title{
DEVELOPMENT OF AN IN VITRO RNAI TO INVESTIGATE GENE FUNCTION IN BRUGIA MALAYI
}

\author{
By \\ ADEL MOHAMMED FARGHALY ${ }^{1}$, HANY ABD EL-HAI AFIFY ${ }^{1}$ \\ AFAF ABD EL-RAOUF TAHA ${ }^{1 \bullet}$ and EMAN MOSTAFA ${ }^{1,2}$ \\ Department of Parasitology ${ }^{1}$, Faculty of Medicine, Zagazig University, Egypt, \\ and Department of Infectious Diseases ${ }^{2}$, University of Georgia, 501 D.W. \\ Brooks Drive, Athens, GA, USA ( ${ }^{*}$ Correspondence: drafaf343@yahoo.com)

\section{Abstract}

The RNA interference (RNAi) has the ability to turn off individual gene expression. So, it affords a remarkably specific tool for studying the effects of genes. It is regarded as a direct approach for determining such gene/genes functions and offers a valuable tool for modern drug discovery. The study aimed to develop in vitro RNAi in Brugia malayi with particular interest to study the function of Brugia malayi avr-14 (Bm-avr-14) and Brugia malayi $\beta$-tubulin (Bm- $\beta$-tubulin) genes. Bm-avr-14 is a gene encoding glutamate gated chloride channel ( $\mathrm{GluCl}$ ) which binds ivermectin and Bm- $\beta$-tubulin is a gene encoding $\beta$-tubulin which binds albendazole. Adult female worms were soaked in heterogeneous short interfering RNA (hsiRNA) with interest to study the role of two genes Bm-avr-14 and Bm- $\beta$ tubulin. Then, we assessed the knock down effects of target genes using worminator system and real time PCR. We found that worms treated with hsiRNA of Bm-avr-14 had a significant reduction in microfilariae $(\mathrm{mf})$ production in comparison with untreated worms or worms treated with hsiRNA of green fluorescent protein (GFP). No significant reduction in mf production with Bm- $\beta$-tubulin gene was obtained. There were no changes in the movement of adults treated with either Bm-avr-14 or Bm$\beta$-tubulin hsiRNAs. Inconsistent RNAi mediated suppression was achieved with Bm-avr-14 and Bm- $\beta$ tubulin using real time PCR. The data may be helpful in assessment of drug target potential of genes.

Keywords: Brugia malayi; Filarial nematode; Gene function; RNAi.

\section{Introduction}

Lymphatic filariasis (LF) is a mosquitoborne parasitic infection that causes elephantiasis and hydrocele, which makes the patients less productive and socially rejected. It causes significant socio-economic losses and morbidity. The impact of this disease is considerable over one hundred twenty million people are infected in 73 endemic countries (Oscar et al, 2014). In an effort to minimize morbidity and control transmission of the disease, the Global Program for the Elimination of Lymphatic Filariasis began mass drug administration (MDA) program primarily based on repeated dosing of either diethylcarbamazine citrate and albendazole, or albendazole and ivermectin in areas where the other filariae, Onchocerca volvulus and Loa loa are coendemic. This program was contributed in prevalence reduction in many areas, but didn't change the fact that lymphatic filariasis remains a global health problem (Ottesen et al, 2008).
Many factors still contribute to the persistence of this problem, but central was the lake of effective drugs; as none of the MDA drugs are effective against all stages of the parasite life cycle especially the adult worms (Pax et al, 1988). This reflects the necessity of providing MDA annually to cover the lifespan of the adult worms. Failure to control the infection was due to the lack in understanding the mechanism of action and drugs pharmacology used in the treatment of the infection like DEC and ivermectin. Thus, it was mandatory to start a more massive research to have a deeper perception of the pharmacodynamics of the current drugs (Geary et al, 2010). An important impediment to rational development of such drugs was the experimental intractability of parasitic nematodes. An example of this complication is RNA interference (RNAi), a reverse genetic tool that helped to 'turn off' genes of interest rapidly and specifically. RNAi has quickly become a standard tool in rational drug discovery for the identification 
and validation of potential new drug targets (Bartz and Jackson, 2005; Taylor et al., 2007). By suppressing specific genes and analyzing the resulting phenotype, it is possible to delineate gene function and appraise the potential value of encoded proteins as drug targets. Successful applications of current RNAi protocols to parasitic nematodes were sporadically reported, limited in their effectiveness and seldom repeated (Geldhof et al, 2007). Success was achieved with Nippostrongylu sbrasiliensis (Hussein et al, 2002), Ascaris suum (Islam et al, 2005; Xu et al, 2010), Trichostrongylus colubriformis (Issa et al, 2005), Ostertagia ostertagi (Visser et al, 2006), and Haemonchus contortus (Geldhof et al, 2006). Also, RNAi was described in $B$. malayi (Aboobaker and Blaxter, 2003; Ford et al, 2009), Onchocerca volvulus (Lustigman et al, 2004; 2005) and Litomosoides sigmodontis (Pfarr et al, 2006).

However, the successful RNAi "only works on a limited number of genes, and in some cases the effect was small and difficult to reproduce" (Geldhof et al, 2006). To date, the application of RNAi in parasitic nematodes has met with both success and significant problems. For parasitic nematodes such as Ascaris suum, RNAi appears to be robust and reliable. But for others such as $H$. contortus, RNAi is both unreliable and sometimes unattainable. The absence of RNAi protocols with parasitic nematodes impedes identification and validation of new drug targets, to a better understanding of anthelmintic mode of action, and to advancing our comprehension of parasite biology. Control of lymphatic filariasis relies on three main drugs; ivermectin which binds with high affinity to glutamate gated chloride channel (GluCls) that occur in invertebrate nerve and muscle causing an increase in permeability of cell membrane to chloride ions and hyperpolarization in nerve and muscle. Hyperpolarization caused paralysis and worms death (Campbell, 1991). An example of a gene encoding GluCls is avr-14 widely conserved in parasitic nematodes, including $B$. malayi. Function the gene Benzimidazoletype anthelmintics were studied, such as albendazole, exert effect by binding to $\beta$ tubulin and inhibiting microtubule formation. Microtubules have a wide variety of functions as intracellular transport, nutrient (glucose) uptake, cell shape, and synaptic formation among others (McKellar and Scott, 1990). The second choice was the $\beta$ tubulin gene, for evaluation. Thirdly, diethylcarbamazine (DEC) that showed to overstimulate parasite neuromuscular systems and increase motility, also to activate complement on parasite surface membranes, but DEC was a poorly understood drug without candidate receptors that can be targeted at present (Maizels and Denham, 1992; Geary et al, 2010).

The present study aimed to develop in vitro RNAi in Brugia malayi with particular attention to study the function of Bm-avr-14 and $B m-\beta$-tubulin genes.

\section{Materials and methods}

Primers for PCR were designed using Eurofins MWG Operon Primer Design Tool with the default settings. Primers were provided by Eurofin MWG Operon (AL, USA) (Tab.1). As a negative control green fluorescent protein (GFP) of jelly fish Aequorea victoria was used which is not present in genome of Brugia, to check for any nonspecific phenotypic changes so any changes seen with target genes were not because of toxic or nonspecific effects of RNAi.

Table 1: Primers with T7 sequences designed for dsRNA synthesis

\begin{tabular}{|l|l|c|c|}
\hline Gene & Sequences & $\mathrm{Tm}$ & Expected PCR product \\
\hline Bm- avr-14- & F:TAATACGACTCACTATAGGGAGATTATGATTGGCGTGTACGA & $69.6^{\circ} \mathrm{C}$ & 500 \\
T7 & R:TAATACGACTCACTATAGGGCATGTTTGTCGATCCAACGGA & $70.7^{\circ} \mathrm{C}$ & \\
\hline Bm- $\beta . t u b-\mathrm{T} 7$ & F:TAATACGACTCACTATAGGGCGACTGCTTGCAGGGTTTTC & $71.9^{\circ} \mathrm{C}$ & 600 \\
& R:TAATACGACTCACTATAGGGTGTGTGAGTTCAGCAACGGT & $70.8^{\circ} \mathrm{C}$ & \\
\hline \multirow{2}{*}{ GFP-T7 } & F:TAATACGACTCACTATAGGGCCATGGCCAACACTTGTCAC & $71.9^{\circ} \mathrm{C}$ & 200 \\
& R:TAATACGACTCACTATAGGGCTGGTAAAAGGACAGGGCCA & $71.9^{\circ} \mathrm{C}$ & \\
\hline
\end{tabular}


Parasites: $B$. malayi $\mathrm{mf}$ and adult female were sourced from the National Institute of Allergy and Infectious Diseases (NIAID/ NIH Filariasis Research Reagent Resource Center (FR3; College of Veterinary Medicine, University of Georgia, Athens, GA, USA).

Preparation of heterogeneous short interfering RNA (hsiRNA): RNA extraction was performed on flash frozen $B$. malayi adults and $\mathrm{mf}$ was performed using a modified TRIzol $^{\circledR}$ LS Reagent (Life Technologies) protocol. Samples with a 260/280 ratio above 1.8 were sent to the Georgia Genomics Facility (GGF; Athens, GA) for integrity analysis on an Agilent 2100 Bioanalyzer(Agilent Technologies, Santa Clara, CA, USA) using an RNA 6000 nano chip. Samples with an RNA Integrity Number (RIN) of $\geq 8$ were used as template for synthesis of cDNA using protoscript II First strand cDNA synthesis kit (New EnglandBioLabs, Ipwich, MA, USA) according to manufacturer's instructions. Reactions were run on a T100 ${ }^{\mathrm{TM}}$ Thermal Cycler (Bio Rad, Hercules, CA) using 0.2 thin-walled PCR tubes as follows, $25^{\circ} \mathrm{C}$ for $5 \mathrm{~min}, 42^{\circ} \mathrm{C}$ for an hour, $85^{\circ} \mathrm{C}$ for $5 \mathrm{~min}$.

PCR was performed on cDNA using IProof High-Fidelity DNA Polymerase) (Bio-Rad). PCR primers contained T7 promoter sequences followed by two guanine base at their 5' ends for transcription by $\mathrm{T} 7$ RNA polymerase and enhanced transcription yield. Primers were designed to yield a PCR product corresponding to $500 \mathrm{bp}, 600 \mathrm{bp}$ and $200 \mathrm{bp}$ of the transcript selected for gene silencing. Reactions were run on a T100 ${ }^{\mathrm{TM}}$ Thermal Cycler (Bio Rad, Hercules, CA) as follows, initial denaturation at $98^{\circ} \mathrm{C}$ for $30 \mathrm{~s}$, denaturation at $98^{\circ} \mathrm{C}$ for $10 \mathrm{~s}$, annealing variable for $30 \mathrm{~s}$, extension at $72^{\circ} \mathrm{C}$ for $15 \mathrm{~s}$, followed by 34 cycles of denaturation at $98^{\circ} \mathrm{C}$ for $10 \mathrm{~s}$, final extension at $72^{\circ} \mathrm{C}$ for $5 \mathrm{~min}$. The products were then run on a $2 \%$ agarose gel to ensure amplification of only one product. Samples that resulted in one band of the correct size were subjected to qPCR. Upon completion, gels were visualized under a transilluminator (Syngene, Frederick, MD) using GeneSnap software v 7.12.06.

Purification of PCR products was done using QuickLink pure PCR purification kit as the manufactures instructions (Invitrogen Life technologies, Carlsbad, CA, USA

PCR products were cloned into the zero blunt $^{\circledR}$ TOPO $^{\circledR}$ PCR cloning kit (Invitrogen by life technologies) according to the manufacturer's instructions. Briefly, $4 \mu 1$ of the PCR product, $1 \mu \mathrm{l}$ salt solution (kit reagent) and $1 \mu \mathrm{lpCR} \circledast I I-$ Blunt-TOPO cloning vector were combined and gently mixed. After 5 min incubation at room temperature (22$23^{\circ} \mathrm{C}$ ), reaction was placed on ice and proceeds to transforming OneShot ${ }^{\circledR}$ competent cells. $2 \mu \mathrm{l}$ of the reaction mixture was added to chemically competent Escherichia coli (E. coli) bacteria TOP 10 (supplied with the kit), and incubated for $10 \mathrm{~min}$ on ice. Then, cells were heat-shocked for 30 seconds at $42^{\circ} \mathrm{C}$ without shaking. Immediately the tubes were transferred to ice for 2 minutes then, $250 \mu 1$ S.O.C medium was added to reaction. The tube was capped tightly and shaked horizontally (200rpm) at $37^{\circ} \mathrm{C}$ for an hour. $130 \mu \mathrm{l}$ of the transformed bacteria solution were spread on pre-warmed agar plates containing kanamycin $(50 \mu \mathrm{g} / \mathrm{ml})$. Plates were incubated overnight at $37^{\circ} \mathrm{C}$. 10 colonies was taken and cultured overnight in 2x YT medium containing antibiotic kanamycin at concentration of $50 \mu \mathrm{g} / \mathrm{ml}$.

Plasmid preparation and digestion: Plasmid DNA was isolated using GenElute ${ }^{\mathrm{TM}}$ Plasmid Miniprep Kit (Sigma) as described by the manufacturer. For harvesting, $1 \mathrm{ml}$ of overnight recombinant $E$. coli culture was pelleted by centrifugation at $\geq 12,000 \mathrm{xg}$ for 1 minute and the supernatant was discarded, the bacterial pellet was resuspended with $200 \mu 1$ of the Resuspension Solution (supplied with kit) and vortexed to thoroughly resuspend the cells until homogeneous. Cells were lysed by adding $200 \mu 1$ of the Ly- 
sis solution (supplied with kit). The contents was mixed gently by inversion (6-8 times) until the mixture become clear and viscous without vortex and after a maximum of 5 minutes, the cell debris was precipitated by adding $350 \mu \mathrm{l}$ of the Neutralization /Binding solution (supplied with kit) and gently tubes were inverted 4-6 times. Cell debris was pelleted by centrifuging at maximum speed for 10 minutes. A GenElute Miniprep binding column was inserted into a micro centrifuge tube and $500 \mu \mathrm{l}$ of the column preparation solution was added to each miniprep column and centrifuged at $12,000 \times \mathrm{g}$ for 1 minute and flow- through liquid was discarded. The cleared lysate was transferred to the prepared column and centrifuged at $\geq 12,000 \mathrm{xg}$ for 1 minute and the flow-through liquid was discarded. $750 \mu \mathrm{l}$ of diluted Wash Solution (supplied with kit) was added to column and centrifuge at $\geq 12,000 \times \mathrm{g}$ for 1 minute. The column was transferred to a fresh collection tube and $50 \mu 1$ of molecular biology reagent water was added to column. Recovery and purity was determined by spectrophotometric analysis. To make sure that we had cloned PCR product, we digested the plasmid using EcoR1 enzyme and EcoR1 buffer (NEW ENGLAND, Bio Labs) in 0.2 $\mathrm{ml}$ PCR tube by adding $3 \mu 1$ plasmid DNA, $1 \mu 1$ of Eco R1 enzyme, $2 \mu 1$ of EcoR1 buffer $\mathrm{x} 2$, and $14 \mu 1 \mathrm{H} 2 \mathrm{o}$. The reaction was kept in PCR machine at $37^{\circ} \mathrm{C}$ for an hour and after that was run on the $1 \%$ agarose gel to see bands.

Long-term bacterial storage: To prepare a frozen permanent stock solution, fresh overnight culture was made and took $1 \mathrm{ml}$ of bacterial culture added to $1 \mathrm{ml}$ of glycerol $40 \%$ in $2 \mathrm{ml}$ cryogenic vials (Corning). Tubes were inverted 4-6 times to mix gently and then stored at $-80^{\circ} \mathrm{C}$ until further use.

Sequencing of plasmid insert and Blast: At the same time, long term bacterial storage was made; samples with highest concentration were sent for sequencing to make sure that we cloned the correct gene. plasmid $<6$ $\mathrm{kb}$, final concentration $50 \mathrm{ng} / \mu \mathrm{l}$ in total vol- ume $10 \mu \mathrm{l}$ was prepared and shipped to GENEWIZ, NJ, USA. The result from GENEWIZ was used to do basic local alignment search tool (BLAST) using the website http://blast.ncbi.nlm.nih.gov/ by entering the results of sequencing s of $a v r-14$ as query sequence and compare it with known sequences of $a v r-14$ gene which we used it as a subject sequence.

Double strand RNA production (dsRNA): The dsRNA corresponding to the gene to be targeted by RNAi was prepared using T7 Quick High Yield RNA synthesis kit approximately $1 \mu \mathrm{g}$ of PCR product was used in a $20 \mu \mathrm{l}$ reaction according to recommended protocol (New England BioLabs). Reaction was mixed thoroughly and pulse-spin in microfuge and incubated at $37^{\circ} \mathrm{C}$ for 2 hours for transcript $>0.3 \mathrm{~kb}$ and for longer time up to overnight incubation for transcript $<0.3$ $\mathrm{kb}$. Then checked by loading $1 \mu \mathrm{l}$ on a $1.5 \%$ agarose gel using ultra-pure agarose gel ( Invitrogen by Life Technologies) alongside ds RNA ladder (New England, Bio Labs).

Purification of double strand RNA by isopropanol precipitation: When a suitable RNA band was visualized, the reminder of sample was purified by isopropanol precipitation as follows: one volume of RNase-free water was added to the sample of ds RNA plus one volume of isopropanol (Fisher scientific Bio Reagents) and 1/10 volume $3 \mathrm{M}$ sodium acetate ( $\mathrm{pH}$ 5.2) (Sigma) was added to ds RNA reaction, incubated at RT for 5 mins and then centrifuged 16,000x g, $10 \mathrm{~min}$ at RT. Supernatant was replaced with one vol 70\% ethanol (Sigma-Aldrich) Incubated at RT, $5 \mathrm{~min}$. Centrifuged at 16,000x g, 5 min at RT. Supernatant was removed and pellet was air dried. Before pellet completely dried, it was resuspended in $50 \mu 1$ RNasefree $\mathrm{H}_{2} \mathrm{O}$.

Processing of dsRNA into hsiRNA with ShortCut RNase III:The purified long dsRNA were processed to heterogeneous short interfering RNA (hsiRNA) using shortcut RNase III as recommended (New England BioLabs). 
Purification of hsiRNA by ethanol precipitation: After purification an aliquot was examined by gel electrophoresis ( $2 \%$ agarose) gel using ultra-pure agarose gel (Invitrogen by life technologies) alongside siRNA marker (New England BioLabs). Quantification of hsiRNA was done using a NanoDrop 2000 Spectrophotometer (Thermo Fisher Scientific).

Soaking adults in hsiRNA (Landmann et al, 2012): in a laminar flow hood, the appropriate amount of the hsiRNA $(1-2 \mu \mathrm{M})$ was placed in wells of a 24-well cell culture plate to which $1 \mathrm{ml}$ Worm Culture Medium (WCM) was added. [WCM: RPMI-1640 cell culture medium with L-glutamine (Invitrogen, Carlsbad, CA, USA), $1 \%$ glucose, $100 \times$ antibiotic-antimycotic solution (SigmaAldrich, St Louis, MO, USA) and 10\% fetal bovine serum inactivated at $56^{\circ} \mathrm{C}$ for 30 minutes (Invitrogen)]. Two female worms were transferred to each well using a curved pick. The medium was replaced every 12 hours by pipetting hsiRNA into new wells, adding fresh WCM and then transferring the worms. Typically 1-2 $\mu \mathrm{M}$ hsiRNA was used. Controls included worms cultured similarly but in the absence of any RNA and same concentration (1-2 $\mu \mathrm{M}$ hsiRNA) of GFP. Worms were incubated in a $37^{\circ} \mathrm{C}, 5 \% \mathrm{CO} 2$ incubator (Thermo scientific USA). Exposure to the hsiRNA mixture was continued for 2-5 days.

At every time point (every 12 hours), the collected $\mathrm{mf}$ from both treated and untreated samples was liquated to measure the motility of $\mathrm{mf}$. The $\mathrm{mf}$ was counted, and then spin down by centrifuge at 3000rpm for 30 minutes. The collected mf was kept in RNA later in $-80^{\circ} \mathrm{C}$. for RNA extraction later by TRIZOL LS Reagent and subsequent cDNA synthesis. At the end of experiment, the movement of the adults was measured by worminator along with video documentation of the worm movements.

Worminator (WormAssay) (Storey et al., 2014):From Worm culture medium containing $\mathrm{mf}$ collected every 12 hour, $50 \mu \mathrm{l}$ was pipetted into 384 well plates and examined using worminator system. The movement of adults at end of experiment was also recorded using Worm Assay approximately for $1 \mathrm{~min}$. Recorded mean movement unit of worms was stored in Excel spreadsheets.

Relative Quantitative RT-PCR: Total RNA of $B$. malayi from either microfilariae or adults was extracted using TRIzol ${ }^{\circledR}$ LS Reagent (Life Technologies). This RNA was used as a template for cDNA synthesis using Protoscript II First strand cDNA synthesis kit (New England, BioLabs, Ipwich, MA, USA). PCR was performed on cDNA using I Proof High-Fidelity DNA Polymerase. The products were then run on a $2 \%$ agarose gel to ensure proliferation of only one product. Samples that resulted in one band of the correct size were subjected to efficiency curve after calculation of their concentration using the NanoDrop 2000 Spectrophotometer (Thermo Fisher Scientific). Primers (Tab. 2), was diluted to final concentration of $200 \mathrm{nM}$. Master Mix was made up as the following $\mathrm{x}$ number of reaction using the PerfeCTa ${ }^{\mathrm{TM}}$ SYBR ${ }^{\circledR}$ GreenFastmix ${ }^{\mathrm{TM}}$, Low ROX ${ }^{\mathrm{TM}}$ (Quanta Biosciences, MD, USA) as follows: 12.5 $\mu \mathrm{l}$ SYBR mix,2.5 forward primer, 2.5 reverse primer $2.5 \mu \mathrm{H} 20$ and $5 \mu 1$ template ( Total $25 \mu \mathrm{l}$ ) in $0.2 \mathrm{ml}$ thin -walled PCR strips and flat top caps (Corning). Then afterward, total RNA of $B$. malayi from both treated and untreated samples were extracted using TRIzol ${ }^{\circledR}$ LS Reagent (Life Technologies). This RNA was used as a template for cDNA synthesis using Protoscript II First strand cDNA synthesis kit (New England BioLabs, Ipwich, MA, USA). This cDNA served as a template in RT-PCR assays using the PerfeCTa ${ }^{\mathrm{TM}}$ SYBR ${ }^{\circledR}$ GreenFastmix ${ }^{\mathrm{TM}}$, Low ROX ${ }^{\mathrm{TM}}$ (Quanta Biosciences, MD). Quantitative PCR was performed on cDNA using PerfeCTa ${ }^{\text {TM }}$ SYBR $^{\circledR}$ GreenFastmix $^{\mathrm{TM}}$, Low ROX ${ }^{\mathrm{TM}}$ (Quanta Biosciences). Reactions were set up in $0.2 \mathrm{ml}$ thinwalled PCR strips and flat top caps (Corning). Each reaction was run on an $\mathrm{Mx} 3000 \mathrm{P}$ Thermocycler (Stratagene,) using Mx3000 
software v 4.01 for data collection. The program was as follows: $95^{\circ} \mathrm{C}$ for $2: 30 \mathrm{mins}$, $95^{\circ} \mathrm{C}$ for $15 \mathrm{~s}$, variable $55^{\circ}-65^{\circ} \mathrm{C}$ for $45 \mathrm{~s}$, $72^{\circ} \mathrm{C}$ for $1 \mathrm{~min}, 95^{\circ} \mathrm{C}$ for $15 \mathrm{~s}$ for 40 cycle , $95^{\circ} \mathrm{C}$ for $1 \mathrm{~min}, 55^{\circ} \mathrm{C}$ for $30 \mathrm{~s}, 95^{\circ} \mathrm{C}$ for $30 \mathrm{~s}$.

Table 2 Primers designed for Relative Quantitative RT-PCR

\begin{tabular}{|l|c|c|c|}
\hline Gene & Sequences & Tm & PCR product \\
\hline Bm- avr- 14 & F:TTTCTTGGCCAGACACAGGT & $60.4^{\circ} \mathrm{C}$ & 200 \\
& R:CGAACGGTGGTACTTGCGTA & $62.4^{\circ} \mathrm{C}$ & \\
\hline Bm - $\beta$ - tub & F:TTGGTCAAAGTGGTGCTGGT & $60.4^{\circ} \mathrm{C}$ & 149 \\
& R:GCCTCCCAACGAATGAGTGA & $62.4^{\circ} \mathrm{C}$ & \\
\hline Bm cal- -1 & F:GTGCAGCACGTCAACAATCA & $60.4^{\circ} \mathrm{C}$ & 130 \\
& R:ATCGTTCCATTGCCGTCCTT & $60.4^{\circ} \mathrm{C}$ & \\
\hline
\end{tabular}

Statistical analysis: Data were calculated, tabulated and statistically analyzed using windows XP IBM SPSS (Statistical Package for Social Science) version 18.0. Graphes were generated using prism 5. Significance was defined as $\mathrm{P}<0.05$.

\section{Results}

Good quality total RNA was characterized with marker peak at 25 nucleotide (nt), the small 5S, 5.8S and tRNAs was present in the electropherogram between the marker peak and the 200 nucleotide region. Two ribosomal peaks, the $18 \mathrm{~S}$ and $28 \mathrm{~S}$ rRNA peaks. The baseline between the internal marker and the $18 \mathrm{~S}$ rRNA peak is relatively flat and free of small rounded peaks corresponding to smaller RNA molecules that are degradation products of the rRNA transcripts. Sample was eukaryotic RNA (Fig. 1) and RNA integrity number (RIN) of $8.5 / 10$ suggesting the RNA was mostly intact used in cDNA.

The experiments started with the avr-14 as the target gene and control was untreated adults soaked in just WCM, counted microfilariae production every $12 \mathrm{hr}$ in $50 \mathrm{ul}$ of the medium and then calculated total microfilariae production of both treated and untreated groups. A marked significant reduction was noticed in number of $\mathrm{mf}$ production in treated samples. This reduction of $\mathrm{mf}$ production was caused by either off-target effect, toxic or nonspecific effects of RNA or caused by specific knock down effects of target gene (Fig. 3). There was marked reduction in $\mathrm{mf}$ production in treated samples in comparison with both zero RNA medium and GFP treated samples which confirmed the effect of knockdown of avr-14. This data was generated using repeated measures ANOVA with p value was 0.0008 (Fig.4A \&B). The recorded phenotypic changes in $a v r-14$ knock down samples, but without significant reduction in $\mathrm{mf}$ production with $\beta$-tubulin gene (Fig.5 A\&B). There was no significant changes in treated samples in comparison with zero RNA medium with $\mathrm{p}$ value $=0.8$ using paired t test with Welch's correction. Detection of phenotypic changes on movement of adults: There were no changes in the movement of adults treated with either $a v r$ 14 or $\beta$-tubulin hsiRNAs (Fig. 6 A\&B) with $\mathrm{p}$ value $=0.6$ and 0.8 respectively.

The effects of knock down on microfilariae started with Bm-avr-14 gene and time point was $48 \mathrm{hr}$ (Tab. 3), interestingly this time point was sufficient to show effect of knock down of gene with $60 \%$ down regulation of target mRNA with $\mathrm{p}$ value $=0.046$. When experiment was repeated to see the effect of time on knock down we did not get consistent reliable results from real time PCR. There was target gene may be upregulated in some time point. Data were processed using custom Excel files by the efficiency-corrected $(\mathrm{E} \Delta \Delta \mathrm{Cq})$ relative quantification method (Pfaffl, 2001) (Tab. 4) .

Effects of knock down on adults female $B$. malayi at the end of experiment was noticed by extracting RNA with mf. Samples from knock down $\mathrm{Bm}$ - $\beta$-tubulin were used with untreated samples as with $\mathrm{mf}$, and control gene calmodulin like protein as normalized gene (control). Up regulation of target gene by 3 fold was obtained (Tab. 5). 


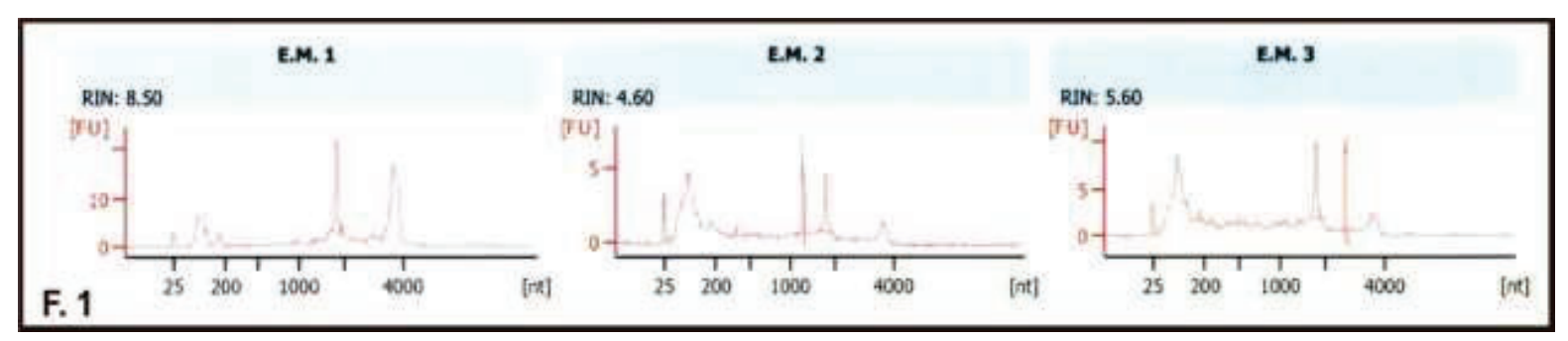

Fig. 1 Agilent Bioanalyzer RNA Electropherograms
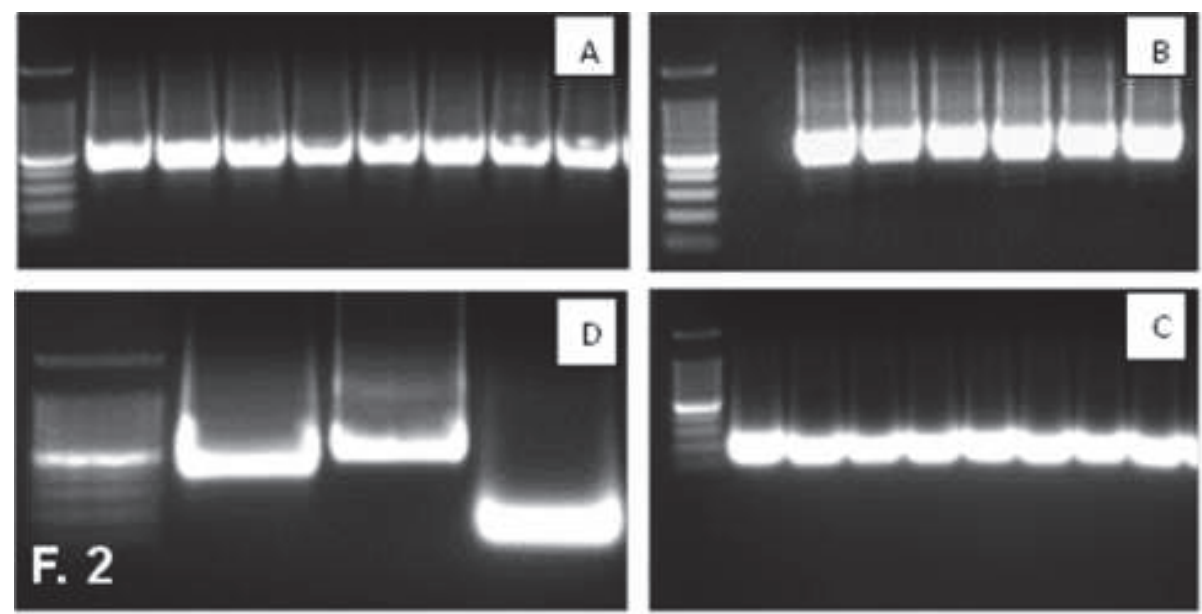

Fig. 2: Gel photos for dsRNA, A: avr-14 500 bp, B: ß-tub 600 bp, C: GFP 200 bp. D: gel photo of three gene in one gel alongside $100 \mathrm{bp}$ ladder (Promega, WI, USA)

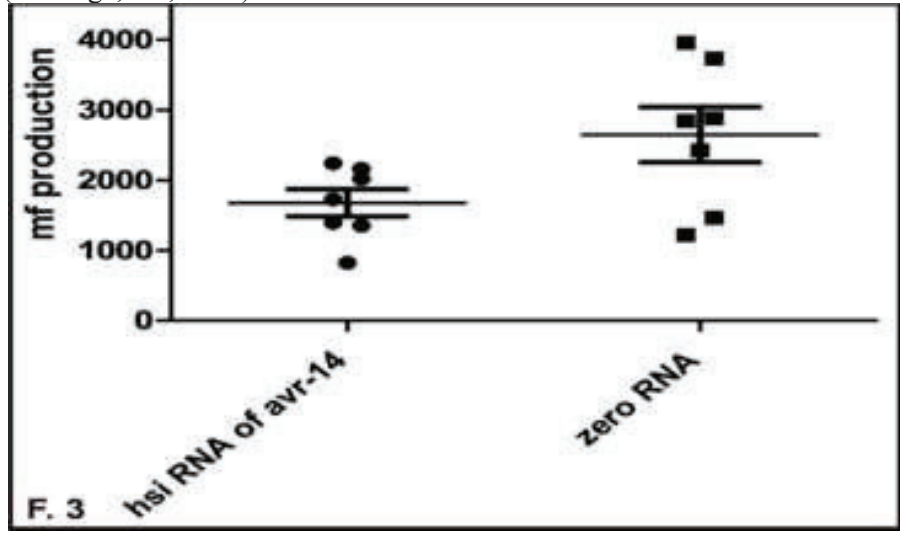

Fig. 3: Effect of knock down of avr-14 on mf production in comparison with zero RNA medium

Table 3: Relative gene expression REST-2009

\begin{tabular}{|c|c|c|c|c|}
\hline Gene & Reaction efficiency & Expression & $95 \%$ C.I. & $p$-value \\
\hline Control & 0.98 & 1.000 & & \\
\hline$a v r-14$ & 0.95 & 0.396 & $0.199-0.791$ & $\underline{0.046}$ \\
\hline
\end{tabular}

Table 4: Ct value of both treated and untreated samples

\begin{tabular}{|c|c|c|c|c|c|c|}
\hline Ct values & \multicolumn{3}{|c|}{$B m-a v r-14$} & \multicolumn{3}{c|}{ Control } \\
\hline Treated samples & 21.75 & 21.76 & 21.80 & 27.33 & 26.47 & 28.03 \\
\hline Untreated samples & 19.97 & 19.53 & 20.14 & 27.02 & 26.57 & 26.66 \\
\hline
\end{tabular}

Table 5: Fold difference of target gene $B m$ - $\beta$-tub in relation to normalized gene cal-1 at end at $72 \mathrm{hr}$

\begin{tabular}{|l|l|l|l|l|l|l|}
\hline Sample & Time & $\begin{array}{l}\text { Average } \mathrm{c}_{\mathrm{T}} \\
\text { Target gene } \\
\beta \text {-tub }\end{array}$ & $\begin{array}{l}\text { Average } \mathrm{C}_{\mathrm{T}} \\
\text { Normalized } \\
\text { gene cal -1 }\end{array}$ & $\begin{array}{l}\Delta \mathrm{c}_{\mathrm{T}} \\
\mathrm{C}_{\mathrm{T}} \quad \beta \text {-tub } \\
\mathrm{C}_{\mathrm{T}} \text { cal }\end{array}$ & $\begin{array}{l}\Delta \Delta \mathrm{c}_{\mathrm{T}} \\
\Delta \mathrm{c}_{\mathrm{T}} \text { treated }- \\
\Delta \mathrm{c}_{\mathrm{T}} \text { untreated }\end{array}$ & $\begin{array}{l}\text { Fold difference in } \beta- \\
\text { tub relative to cal }\end{array}$ \\
\cline { 1 - 8 } Untreated & \multirow{2}{*}{$72 \mathrm{hr}$} & 29.32 & 27.88 & 1.44 & 0 & 1 \\
\cline { 3 - 8 } & & 28.72 & 28.887 & -0.15 & -1.59 & 3.01 \\
\hline Treated & & &
\end{tabular}




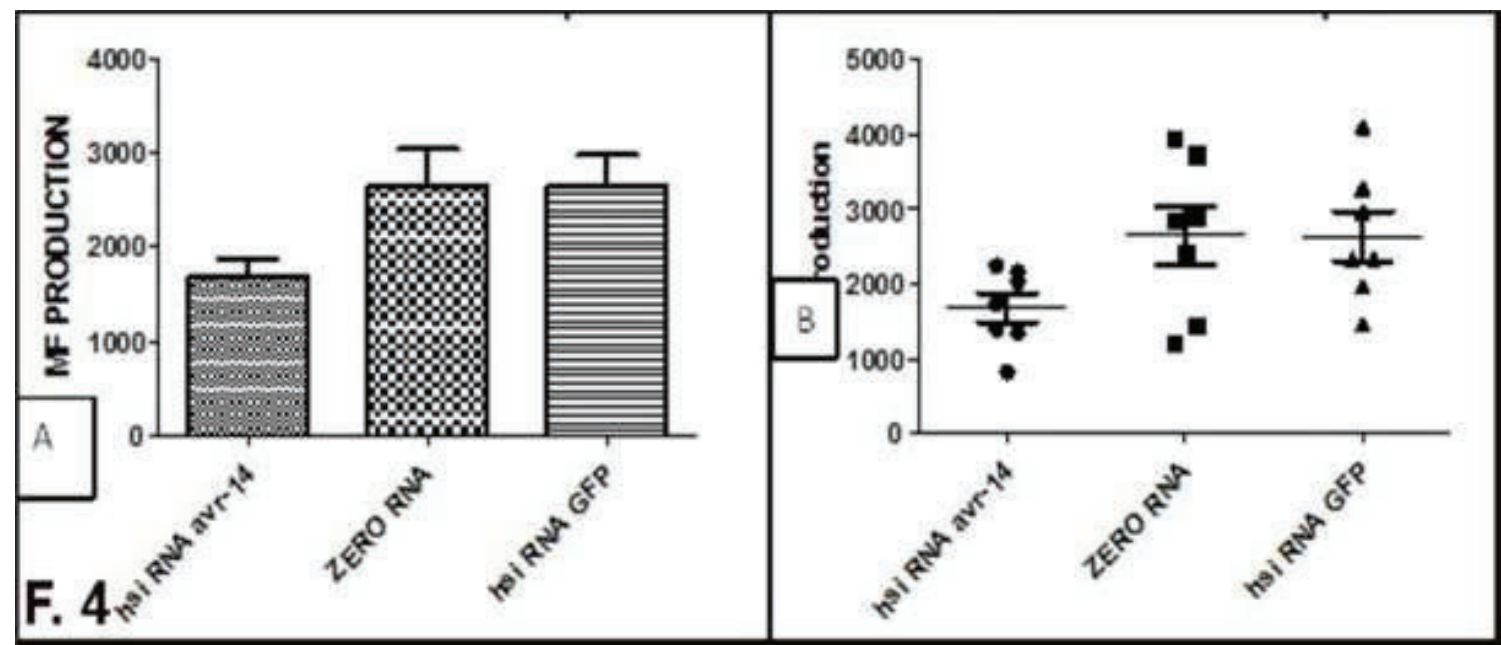

Fig. 4 A, B: Effect of knock down of avr-14 on mf production compared with zero RNA medium and GFP treated samples

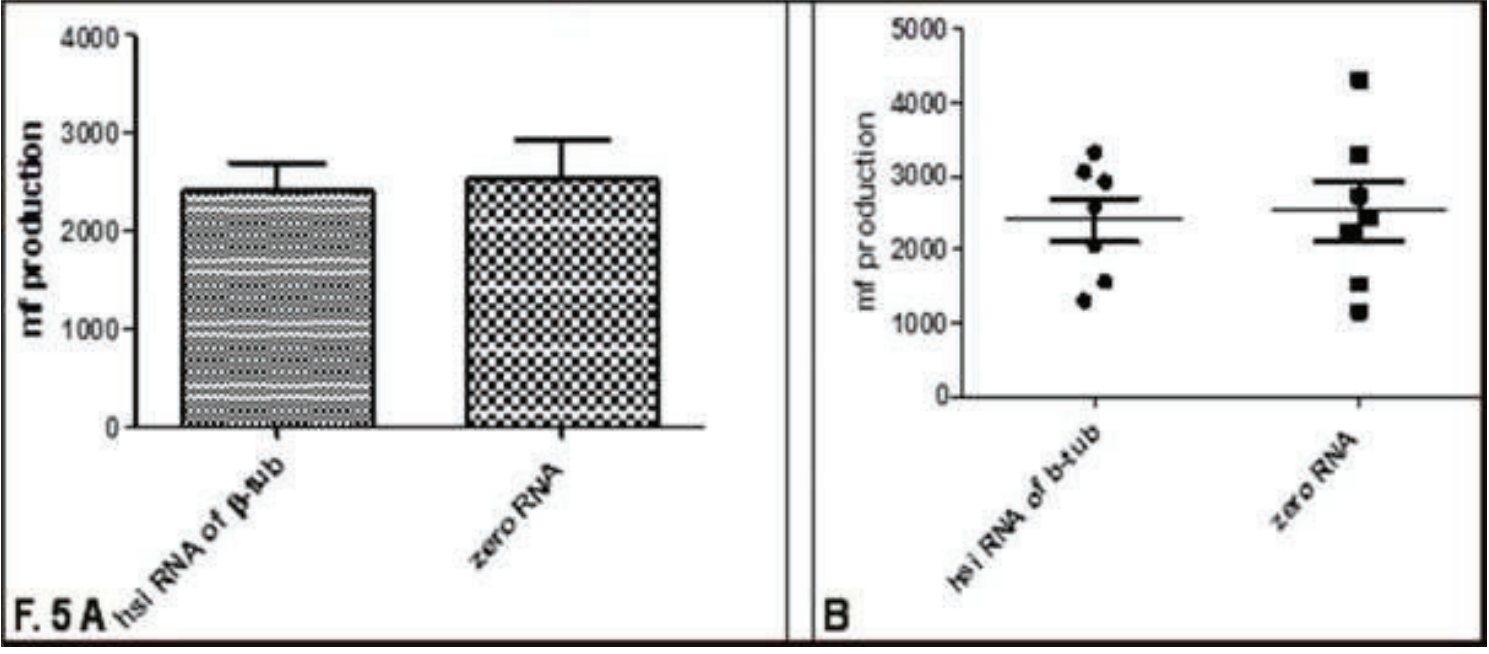

Fig.5 A\&B: Effect of knock down of $\beta$-tubulin on mf production in comparison with zero RNA medium

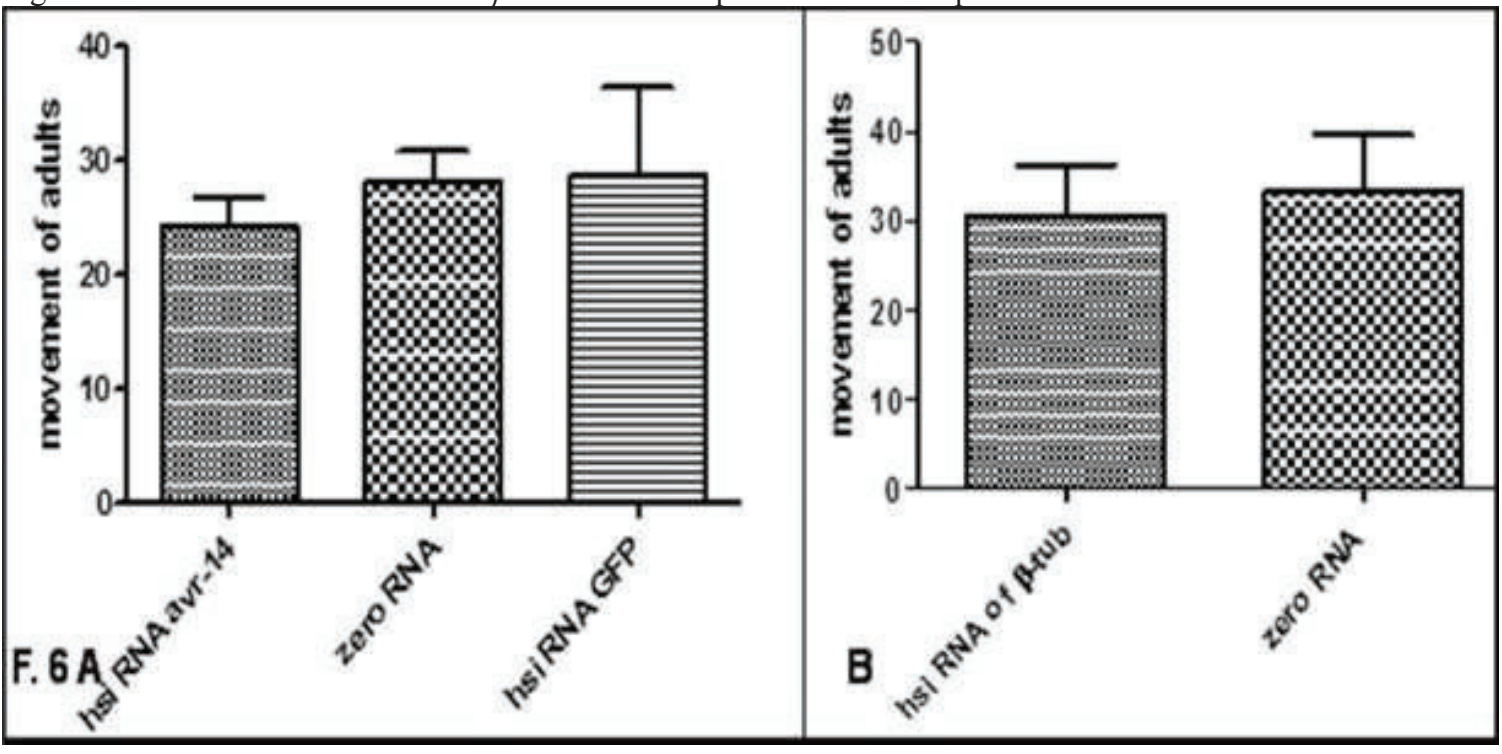

Fig.6 A\& B: Effect of knock down of both avr-14 and $\beta$-tubulin on movement of adult B. malayi in comparison with zero RNA medium and GFP treated samples 


\section{Discussion}

The primary aim was developing in vitro RNAi in Brugia malayi with particular attention to study the Bm-avr-14 gene. We have attempted to modify a previously published method to study our targets of interest the avr-14 gene is highly conserved in freeliving and parasitic nematodes (Laughton et al, 1997; Jagannathan et al, 1999; Dent et al, 2000; Yates and Wolstenholme, 2004; McCavera et al, 2009; El-Abdellati et al, 2011). The gene was alternatively spliced in most species to yield two subunits, GluCla3A and $\alpha 3 \mathrm{~B}$. These subunits share a common N-terminal ligand-binding domain, but they have different $\mathrm{C}$-terminal channelforming domains. An analysis of the $\mathrm{GluCl}$ genome shows the presence of genes that encode four $\mathrm{GluCl}$ subunits including $\mathrm{Bm}$ avr-14A and Bm-avr-14B (Williamson et al, 2007).

The Bm-avr-14 was expressed in a muscle structure surrounded the mf excretorysecretory (ES) vesicle (Moreno et al, 2010). The results showed that treated worms with hsiRNA of Bm-avr-14 resulted in significant reduction $(33.5 \%, 20.16 \%)$ in $\mathrm{mf}$ production compared with untreated worms or treated ones with hsiRNA of GFP respectively. This is consistent with results of ( $\mathrm{Li}$ et al, 2014). They provide evidence for the involvement of Bm-avr-14 in gamete production and embryogenesis in filarial worms, as it is highly expressed in B. malayi developing embryos and reproductive tissues.

This explained the silencing effects of $\mathrm{Bm}$ avr-14 that were highly expressed in reproductive tissues of $B$. malayi. Our data agreed with results suggested that GluCls could be involved in the development of embryos in adult filarial worms (Lie et al, 2014). Strong expression of Bm-avr-14 in early embryos (prelarval stages) suggests that this gene performs an essential function in embryogenesis, and it is consistent with the determined suppressive impact of ivermectin one of the macrocyclic lactone (ML) groups, on embryogenesis reported in previous studies
(Breton et al, 1997; Tompkins et al, 2010). The macrocyclic lactone group of anthelmintics, insecticides, and acaricides acts at GluCls, either activating the channels directly or potentiating their responses to glutamate (Wolstenholme, 2012). The results showed no reduction in movement of adults upon exposure to hsiRNA Bm-avr-14.

Benzimidazole-type anthelmintics, such as albendazole, exert their effect by binding to $\beta$-tubulin and inhibiting microtubule formation. Microtubules have a wide variety of functions such as intracellular transport, nutrient (glucose) uptake, cell shape, and synaptic formation among others. Thus the disruption of microtubule formation interrupts parasite survival in a plenty of ways including preventing the uptake of glucose, inhibiting egg production and impairing muscle movement up to nematode death (McKellar and Scott, 1990; Geary and Kubiak, 2005). While albendazole alone has no anti-filarial effect, when giving in conjunction with either ivermectin or DEC proved to enhance both anti-filarial drugs' potency (Addiss et al, 1997). B. malayi $\beta$-tubulin (Bm- $\beta$-tubulin) was selected as a gene target for progress, but no phenotypic effects with knock down Bm- $\beta$-tubulin, either in mf production or movement of adults. So, Bm- $\beta$-tubulin suppression would not completely abolish motor neuron or gamete production and embryogenesis in adult parasites. Samarasinghe et al.(2011) reported successful suppression of four of six L3s stage $H$. contorts genes by soaking in culture medium containing dsRNA. Exposure to dsRNA for the major excretory secretory protein $H c-a s p-1$ or the highly protective gut amino peptides $\mathrm{Hc}$ H11 resulted in mRNA suppression of $80 \%$ $\& 76 \%$ respectively. Suppression was reproducible in at least 10 separate experiments but no phenotype abnormalities were detected within culture medium.

For real time PCR, although data showed down regulation of $B m-a v r-14$ gene by $60 \%$ in one experiment, these results was not repeatable. Our results did not show consistent 
down regulation of target genes. This is not the first time to report that, Geldhof et al. (2006) suppressed RNAi Haemonchus contortus vacuolar ATPase Hc-vha-10 using electroporation and soaking resulted in the up-regulation of Hc-vha-10 expression. Quantitative RT-qPCR confirmed considerable up-regulation (341\%) of Bm-pc-2 with $B m-p c-2$ dsRNA exposure resulted in a three to four fold transcription increase (Song et al, 2010). The adverse culture conditions led to the increased expression, resulting in saturation of available RISC proteins, which would intervene with the organism's ability to direct an RNAi response to an exogenous trigger. If such saturation events varied between cells and/or tissues, then this may account for differing knock down susceptibilities between some genes (Dalzell et al, 2011). Geldhof et al. (2006) reported that it was only successful in suppressing two of the five genes examined the usage of the soaking method. Hc-sec-21 suppression proved unreliable due to the fact that RNAimediated suppression used to be no longer achieved in two out of five experimental repeats. Microscopic examination of $H$. contortus larvae soaked in fluorescently labeled cathepsin L (Hc-cpl-1) dsRNA containing medium showed very little dsRNA uptake. Thus, soaking technique seemed to be unreliable with variation between experiments and recalcitrance for specific genes. (Viney and Thompson (2008) explained the poor success of RNAi in parasitic nematodes. They attributed that to two major reasons, the external supply of RNA to parasitic nematodes is inappropriate to achieve RNAi and parasitic nematodes are functionally defective in genes required to provoke RNAi from externally supplied RNA. RNAi can also provide an excellent capability to study the function of target genes, but regrettably RNAi in parasitic nematodes was riddled with problems, due to the fact that they once outside host body undergo biological changes that render them resilient to exogenously induced RNAi. No matter how similar the in vitro culture medium is to the host environment, there are still subtle variations that parasitic nematodes may also require (Song et al, 2010).

Hypotheses to explain RNAi difficulties in parasitic nematodes included (i) lack of suitable in vitro culture systems for parasitic nematodes (Geldhof et al, 2006); (ii) inappropriate techniques of dsRNA delivery, i.e. delivered externally, where microinjection directly into the worm is more effective in C. elegans (Viney and Thompson, 2008); (iii) variations in RNAi effector protein performance (Geldhof et al, 2006; Viney and Thompson, 2008) and (iv) variations in the complement of RNAi effectors between nematodes (Knox et al, 2007; Lendner et al, 2008). The latter hypothesis had variations for apicomplexan Plasmodium spp. which were refractory to RNAi due to deficiencies in key pathway elements (Blackman, 2003; Baum et al, 2009). Others point out that RNAi gene silencing in animal nematodes was possible, however that only some genes prone to be susceptible to silencing using current techniques (Britton et al, 2012).

\section{Conclusion}

RNA interference mediated knock down and subsequent examination of the resulting phenotype may be helpful in assessment of potential drug target of genes. Further investigation for RNAi in Brugia malayi is needed. Changing method in hsiRNA delivery was recommended to microinjection instead of soaking to minimize RNA needed.

\section{Acknowledgments}

The authors would like to thanks Prof. Dr. Adrian Wolsten-holme and Dr. Barbara Reaves for their kind help. Thanks are also due to Dr. Andrew Moorhead and NIAID/ NIH Filariasis Research Reagent Resource Center FR3 for providing the filariae parasites used.

\section{References}

Aboobaker, AA, Blaxter, ML. 2003: Use of RNA interference to investigate gene function in the human filarial nematode parasite Brugia malayi. Mol. Biochem. Parasitol. 129, 1:41-51.

Addiss, DG, Beach, MJ, Streit, TG, Lutwick, S, LeConte, FH, et al, 1997: Randomised 
placebo-controlled comparison of ivermectin and albendazole alone and in combination for $\mathrm{Wu}$ chereria bancrofti microfilaraemia in Haitian children. Lancet 350, 9076: 480-4.

Bartz, S, Jackson, AL. 2005: How will RNAi facilitate drug development? Science Signaling 295:39.

Baum, J, Papenfuss, AT, Mair, GR, Janse, C J, Vlachou, D, et al, 2009: Molecular genetics and comparative genomics reveal RNAi is not functional in malaria parasites. Nucl. Acids Res. 37, 11:3788-98.

Blackman, MJ, 2003: RNAi in protozoan parasites: what hope for the Apicomplexa? Protist 154, 2:177-80.

Breton, B, Diagne, M, Wanji, S, Bougnoux, ME, Chandre, F, et al, 1997: Ivermectin and moxidectin in two filarial systems: resistance of Monanema martini; inhibition of Litomosoides sigmodontis insemination. Parassitol. 39, 1:19-28.

Britton, C, Samarasinghe, B, Knox, D, 2012: Ups and downs of RNA interference in parasitic nematodes. Exp. Parasitol. 132, 1: 56-61.

Campbell, WC, 1991: Ivermectin as an antiparasitic agent for use in humans. Ann. Rev. Microbiol. 45, 1: 445-474.

Dalzell, JJ, McVeigh, P, Warnock, ND, Mitreva, M, Bird, DM, et al. 2011: RNAi effector diversity in nematodes. PLoS Negl. Trop. Dis. 5, 6: e1176.

Dent, JA, Smith, MM, Vassilatis, DK, Avery, L. 2000: The genetics of ivermectin resistance in Caenorhabditis elegans. Procee. Nat. Acad. Sci. 97, 6: 2674-9.

El-Abdellati, A, De Graef, J, Van Zeveren, A, Donnan, A, Skuce, P, et al. 2011: Altered avr14B gene transcription patterns in ivermec-tinresistant isolates of the cattle parasites, Cooperia oncophora and Ostertagia ostertagi. Int. J. Parasitol. 41, 9:951-7.

Ford, L, Guiliano, DB, Oksov, Y, Debnath, A K, Liu, J, et al. 2005: Characterization of a novel filarial serine protease inhibitor, Ov-SPI-1, from Onchocerca volvulus, with potential multifunctional roles during development of the parasite. J. Biol. Chem. 280, 49: 40845-56.

Ford, L, Zhang, J, Liu, J, Hashmi, S, Fuhrman, JA, et al. 2009: Functional analysis of the cathepsin-like cysteine protease genes in adult Brugia malayi using RNA interference. PLoS Negl. Trop. Dis. 3, 2: e377.

Geary, TG, Kubiak, TM. 2005: Neuropeptide G-protein-coupled receptors, their cognate lig- ands and behavior in Caenorhabditis elegans. Trends Pharmacol. Sci. 26, 2: 56-58.

Geary, TG, Woo, K, McCarthy, JS, Mackenzie, CD, Horton, J, et al. 2010: Unresolved issues in anthelmintic pharmacology for helminthiases of humans. Int. J. Parasitol. 40, 1: 1-13.

Geldhof, P, Murray, L, Couthier, A, Gilleard, JS, McLauchlan, G, et al. 2006: Testing the efficacy of RNA interference in Haemonchus contortus. Int. J. Parasitol. 36, 7: 801-810.

Geldhof, P, Visser, A, Clark, D, Saunders, G, Britton, C, et al. 2007: RNA interference in parasitic helminths: current situation, potential pitfalls and future prospects. Parasitology 134, 05: 609-19.

Hussein, AS, Kichenin, K, Selkirk, ME. 2002: Suppression of secreted acetylcholinesterase expression in Nippostrongylus brasiliensis by RNA interference. Mol. Biochem. Parasitol. 122, 1:914.

Islam, MK, Miyoshi, T, Yamada, M, Tsuji, N. 2005: Pyrophosphatase of the roundworm Ascaris suum plays an essential role in the worm's molting and development. Infect. Immun. 73, 4: 1995-2004.

Issa, Z, Grant, W, Stasiuk, S, Shoemaker, C, 2005: Development of methods for RNA interference in the sheep gastrointestinal parasite, Trichostrongylus colubriformis. Int. J. Parasitol. 35, 9:935-40.

Jagannathan, S, Laughton, DL, Critten, CL, Skinner, TM, Horoszok, L, et al, 1999: Ligand-gated chloride channel subunits encoded by the Haemonchus contortus and Ascaris suum orthologues of the Caenorhabditis elegans gbr-2 (avr14) gene. Mol. Biochem. Parasitol. 103, 2:129-40. Knox, DP, Geldhof, P, Visser, A, Britton, C. 2007: RNA interference in parasitic nematodes of animals: a reality check? Trends Parasitol. 23, 3: 105-7.

Landmann, F, Foster, JM, Slatko, BE, Sullivan, W, 2012: Efficient in vitro RNA interference and immunofluorescence-based phenotype analysis in a human parasitic nematode, Brugia malayi. Parasit Vectors 5:16-9.

Laughton, DL, Lunt, GG, Wolstenholme, AJ, 1997: Alternative splicing of a Caenorhabditis elegans gene produces two novel inhibitory amino acid receptor subunits with identical ligand binding domains but different ion channels. Gene 201, 1:119-25.

Lendner, M, Doligalska, M, Lucius, R, Hartmann, S. 2008: Attempts to establish RNA int- 
erference in parasitic nematode Heligmosomoides polygyrus. Mol. Biochem. Parasitol. 161, 1: 21-31.

Li, BW, Rush, AC, Weil, GJ, 2014: High level expression of a glutamate-gated chloride channel gene in reproductive tissues of Brugia malayi may explain the sterilizing effect of ivermectin on filarial worms. Int. J. Parasitol. 4, 2:71-6.

Lustigman, S, Zhang, J, Liu, J, Oksov, Y, Hashmi, S, 2004: RNA interference targeting cathepsin L and Z-like cysteine proteases of Onchocerca volvulus confirmed their essential function during L3 molting. Mol. Biochem. Parasitol. 138, 2:165-70.

Maizels, R, Denham, D. 1992: Diethylcarbamazine (DEC): immunopharmacological interactions of an anti-filarial drug. Parasitology 105, S1:S49-60.

McCavera, S, Rogers, AT, Yates, DM, Woods, DJ, Wolstenholme, AJ. 2009: An ivermectin-sensitive glutamate-gated chloride channel from parasitic nematode Haemonchus contortus. Mol. Pharmacol. 75, 6:1347-55.

McKellar, Q, Scott, E, 1990: The benzimidazole anthelmintic agents-a review. J. Vet. Pharmacol. Ther. 13, 3:223-47.

Moreno, Y, Nabhan, JF, Solomon, J, Mackenzie, CD, Geary, TG, 2010: Ivermectin disrupts the function of the excretory-secretory apparatus in microfilariae of Brugia malayi. Procee. Nat. Acad.Sci. 107, 46:20120-5.

Oscar, R, Lemoine, JF, Direny, AN, Desir, L, Rochars, MB, et al. 2014: Haiti national program for the elimination of lymphatic filariasis: A model of success in the face of adversity. PLoS Negl. Trop. Dis. 8:7-12.

Ottesen, EA, Hooper, PJ, Bradley, M, Biswas, G, 2008: The global programme to elimi-nate lymphatic filariasis: health impact after 8 years. PLoS Negl. Trop. Dis. 2, 10: e317.

Pax, R, Williams, J, Guderian, R, 1988: In vitro motility of isolated adults and segments of Onchocerca volvulus, Brugia pahangi and Acanthocheilonema viteae. Tropical medicine and parasitology: Deutsche Gesellsch. Tech. Zusamm. (GTZ) 39:450-5.

Pfaffl, MW, 2001: A new mathematical model for relative quantification in real-time RT-PCR. Nucleic Acids Res. 29, 9: e45-9.

Pfarr, K, Heider, U, Hoerauf, A, 2006: RNAi mediated silencing of actin expression in adult Litomosoides sigmodontis is specific, persistent and results in a phenotype. Int. J. Parasitol. 36, 6: 661-9.

Samarasinghe, B, Knox, D, Britton, C. 2011: Factors affecting susceptibility to RNA interference in Haemonchus contortus and in vivo silencing of an H11 aminopeptidase gene. Int. J. Parasitol. 41, 1:51-9.

Song, C, Gallup, JM, Day, TA，Bartholom, ay, LC, Kimber, MJ, 2010: Development of an in vivo RNAi protocol to investigate gene function in the filarial nematode, Brugia malayi. PLoS Path. 6, 12:e1001239.

Storey, B, Marcellino, C, Miller, M, Maclean, M, Mostafa, E, et al, 2014: Utilization of computer processed high definition video imaging for measuring motility of microscopic nematode stages on a quantitative scale:"The Worminator". Int. J. Parasitol. 4, 3:233-43.

Taylor, DL, Haskins, JR, Giuliano, KA (2007). High content screening: A powerful approach to systems cell biology and drug discovery (Vol. 356): Springer Science \& Business Media .36777.

Tompkins, J, Stitt, L, Ardelli, B, 2010: Brugia malayi: in vitro effects of ivermectin and moxidectin on adults and microfilariae. Exp. Parasitol. 124, 4:394-402.

Viney, M, Thompson, F, 2008: Two hypo-theses to explain why RNA interference does not work in animal parasitic nematodes. Int. J. Parasitol. $38,1: 43-7$.

Visser, A, Geldhof, P, De Maere, V, Knox, D, Vercruysse, J, et al, 2006: Efficacy and specificity of RNA interference in larval life-stages of Ostertagia ostertagi. Parasitology 133, 6:77783.

Williamson, SM, Walsh, TK, Wolstenholme, AJ, 2007: Cys-loop ligand-gated ion channel gene family of Brugia malayi and Trichinella spiralis: a comparison with Caenorhabditis elegans. Invert. Neurosci. 7, 4:219-26.

Wolstenholme, AJ, 2012: Glutamate-gated chloride channels. J. Biol. Chem. 287, 48:40232-8.

Xu, M, Chen, N, Song, H, Lin, R, Huang, C, et al, 2010: RNAi-mediated silencing of a novel Ascaris suum gene expression in infective larvae. Parasitol. Res. 107, 6:1499-503.

Yates, DM, Wolstenholme, AJ, 2004: Dirofilaria immitis: identification of a novel ligandgated ion channel-related polypeptide. Exp. Parasitol. 108, 3:182-5. 